\title{
Synthesis of novel catalysts for hydrodeoxygenation of bio-oil: guaiacol as a model component
}

\author{
A. Aqsha ${ }^{1}$, N. Mahinpey ${ }^{1}$, L. Katta ${ }^{1}$, L. Gras ${ }^{1}$ \& C. J. Lim ${ }^{2}$ \\ ${ }^{I}$ Department of Chemical and Petroleum Engineering, \\ Schulich School of Engineering, University of Calgary, Canada \\ ${ }^{2}$ Department of Chemical and Biological Engineering, \\ University of British Columbia, Canada
}

\begin{abstract}
In this work, NiMo/Support catalysts have been prepared by impregnation technique and evaluated for hydrodeoxygneation (HDO) reaction of guaiacol (GUA) aiming at the identification of active catalysts. Among various catalysts, $\mathrm{NiMo} / \mathrm{TiO}_{2}$ was chosen to understand the influence of reaction parameters, such as temperature, reaction time, $\mathrm{H}_{2}$ pressure, and quantity of the catalyst. The influence of the metal components on guaiacol conversion is determined by comparing mono ( $\mathrm{Ni}$ and $\mathrm{Mo}$ ) metals deposited $\mathrm{TiO}_{2}$. These results signify the alloying nature of metal components. GCMS results showed that phenol is a major component in all the conditions. As there is an increase in the temperature (200, $\left.250,300,350^{\circ} \mathrm{C}\right)$, reaction time $(1,5,8,24 \mathrm{~h}), \mathrm{H}_{2} /$ guaiacol molar feed ratio $(0$, $1: 2,1: 1$, and $2: 1)$, and catalyst amount $(0,25,50,100 \mathrm{mg})$, the conversion has increased significantly while maintaining the high selectivity to HDO products without ring opening reactions. Under optimized conditions $\left(350^{\circ} \mathrm{C}\right.$ and $2: 1$ of $\mathrm{H}_{2}$ : guaiacol ratio), $98 \%$ guaiacol is converted on $\mathrm{NiMo} / \mathrm{TiO}_{2}$ resulting phenol, poly methyl substituted phenols, and traces of cyclohexanone and benzene. It is remarkable that a low amount of catechol dimethyl ether and no indication of catechol and creosol were detected.
\end{abstract}

Keywords: catalyst, guaiacol, hydrodeoxygenation, impregnation, phenol.

\section{Introduction}

Instability of fossil fuels prices, carbon dioxide emissions and inevitable energy demand for future generations bring tremendous attention for alternate fuels (Huber et al. [1]; McKendry [2]). Production of fuels from biomass is a 
considerable alternate and the thermochemical treatment is a valid approach for efficient biomass conversion. Pyrolysis of biomass gives bio-oil, a process that is relatively well developed (Mortensen et al. [3], González-Borja and Resasco [4], Sun et al. [5]). Chemical instability, small miscibility with hydrocarbons, corrosiveness, more amount of water and oxygen contents and low heating values are however the major drawbacks of bio-oil, which impede its direct application as the fuel (Saidi et al. [6], Nimmanwudipong et al. [7]).

The incompatibility of bio oil with crude oil creates a need for novel catalytic processes to upgrade the oil. Catalytic upgrading routes that are being used are catalytic cracking and hydrodeoxygenation (HDO) (Mortensena et al. [8]). Removal of oxygen from molecules of the bio-oil by zeolite catalytic cracking is economically advantageous since it requires atmospheric pressure without need of hydrogen. Nevertheless, the poor hydrocarbons yields, catalyst deactivation by carbonation deposits are the main drawbacks and burning of these carbon deposits is also a tedious process (Serrano-Ruiz and Dumesic [9]). HDO, a high hydrogen pressure operation is used to decrease the polarity and increase the miscibility with non-polar petrochemicals proposed to be an attracting upgrading strategy. HDO of bio-oil can give a high grade oil equivalent to crude oil and the catalysts that are active for the HDO include noble metals and metal sulfides deposited oxide materials or active carbon, which are similar to those used in the petroleum refining hydrotreatment processes (Saidi et al. [6]). Regardless of the catalysts that used hydrogenolysis and hydrogenation are most predominant reactions in HDO (Yang et al. [10]). Presence of water, carbon and other components can pose adverse effect on conventional metal sulfide catalysts, while the noble metals are less abundant and more expensive.

Most of the HDO reactions are carried at high $\mathrm{H}_{2}$ pressures (up to 200 bar) and high temperatures $\left(\geq 400^{\circ} \mathrm{C}\right.$ ), typical of crude oil hydrotreatment (Zhang et al. [11]). So far, only few reports are dealt with mild operational conditions. Based on aforesaid background, we aim to study HDO reaction using several inexpensive, nonsulfidated and non-noble metal deposited oxide supports under mild conditions ( $\leq 100 \mathrm{psi}$ and $\leq 350^{\circ} \mathrm{C}$ ). To study HDO reaction, we adopted guaiacol which is the representative of phenolic components obtained from lignin derived bio-oil. Herein, effect of operative variables on the catalytic activity and stability, selectivity to deoxygenated products is analyzed, and possible reaction routes were proposed.

\section{Experimental}

\subsection{Catalyst preparation}

Wet impregnation technique is considered to prepare metal deposited catalysts. To impregnate the nickel oxide $(\mathrm{NiO}, 10 \mathrm{wt} \%)$ and molebdinum oxide $\left(\mathrm{MoO}_{3}\right.$, $10 \mathrm{wt} \%)$, adequate amounts of aqueous nickel nitrate hexahydrate $\left(\mathrm{Ni}\left(\mathrm{NO}_{3}\right)_{2} \bullet 6 \mathrm{H}_{2} \mathrm{O}\right)$ and ammonium heptamolybdate $\left(\left(\mathrm{NH}_{4}\right)_{6} \mathrm{Mo}_{7} \mathrm{O}_{24}\right)$ are used. All the chemicals purchased from Alfa Aesar or Aldrich. First, suspension of $\mathrm{TiO}_{2}$ 
(anatase) in the metal precursor solution was stirred on a hot plate at $70^{\circ} \mathrm{C}$ until complete evaporation. The impregnated sample and then oven dried at $110^{\circ} \mathrm{C}$ for $12 \mathrm{~h}$. The dried samples subsequently calcined in air at $500^{\circ} \mathrm{C}$ for $3 \mathrm{~h}$ to obtain final catalysts. Here after, we labelled the metal components $\mathrm{NiO}-\mathrm{MoO}_{3}$ as $\mathrm{NiMo}$.

\subsection{Reaction study}

HDO of guaiacol is carried out in a batch reactor. All the samples are pre-activated at $350^{\circ} \mathrm{C}$ for $2 \mathrm{~h}$ under $1 \mathrm{~atm} \mathrm{H}_{2}$ gas. The experiments were performed in a $30 \mathrm{~mL}$ batch reactor of Swagelok made from stainless steel. $10 \mathrm{wt} \%$ catalyst to guaiacol (Alfa Aesar $>98 \%$ ) were loaded in the reactor. The mixture was then heated to desired temperature using subcritical bath in the requisite hydrogen atmosphere. After completing the reaction, the reactor was placed in an ice bath to bring the reactor to normal temperature. The resultant product was collected by centrifugation followed by filtration in order to separate the product liquid and catalyst. The corresponding amounts of those deoxygenation products were subsequently quantified by GC-MS (Agilent 7890) equipped with a flame ionization detector (FID). HP-5MS capillary column (diameter $0.25 \mathrm{~mm}$, film thickness $25 \mu \mathrm{m}$, length $30 \mathrm{~m}$ ) was used for separation and the column temperature was $100^{\circ} \mathrm{C}$.

Reaction parameters such as, temperature, reaction time, and $\mathrm{H}_{2} /$ guaiacol ratio, catalyst amount are varied using optimized catalyst. Blank reactions (without hydrogen, without catalyst, without hydrogen and catalyst, and bare support) are also carried under identical conditions. HDO of guaiacol was checked to be negligible with sole guaiacol (3.8\%) disclosing the important role of catalyst and hydrogen. We also tested non reduced sample to check the effect of reduction on catalytic performance which is found to be lower than the reduced samples. The nominal experiment was repeated in order to check the reproducibility and the results are noted within $\pm 3 \%$ range. The major products detected in GCMS were: phenol, anisole, cresol, catechol dimethyl ether, and catechol. Trace amount of methanol is also identified from the GCMS (not shown).

\section{Results and discussion}

Screening of different metal based catalysts such as, NiMo $\left(\mathrm{NiO}-\mathrm{MoO}_{3}\right), \mathrm{NiV}$ $\left(\mathrm{NiO}-\mathrm{V}_{2} \mathrm{O}_{5}\right), \mathrm{CoMo}\left(\mathrm{CoO}-\mathrm{MoO}_{3}\right), \mathrm{NiCu}(\mathrm{NiO}-\mathrm{CuO}), \mathrm{MoW}\left(\mathrm{MoO}_{3}-\mathrm{WO}_{\mathrm{X}}\right), \mathrm{NiW}$ $\left(\mathrm{NiO}-\mathrm{WO}_{\mathrm{X}}\right)$, etc., are carried out for $\mathrm{HDO}$ reaction (figure is not shown). Unfortunately performance of any of the catalyst except NiMo was not that expected. 


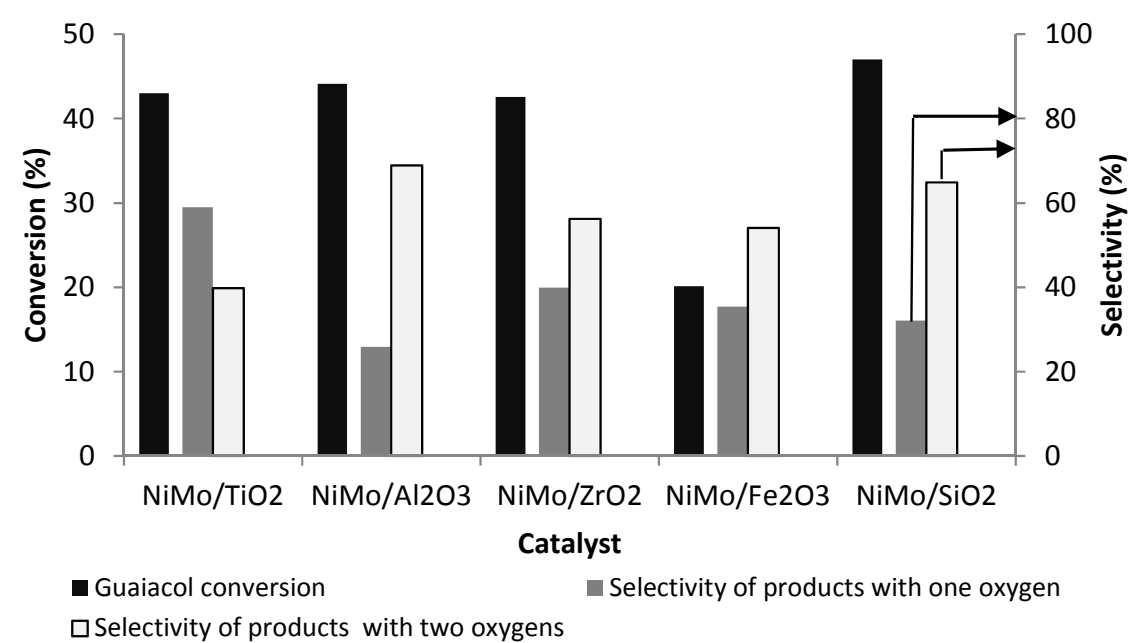

Figure 1: Screening of the catalysts. Reaction conditions: $\mathrm{H}_{2}, 100 \mathrm{psi} ; 10 \mathrm{wt} \%$ catalyst to guaiacol; $300^{\circ} \mathrm{C} ; 5 \mathrm{~h}$.

Activity results of NiMo based catalysts are presented in Figure 1 (selectivity is divided based on the products obtained with one oxygen and two oxygen species). The advantage of NiMo over other metal combinations is, only a small amount of ring saturation $(<2 \%)$ is observed. $\mathrm{NiMo} / \mathrm{SiO}_{2}, \mathrm{NiMo} / \mathrm{TiO}_{2}$, $\mathrm{NiMo} / \mathrm{ZrO}_{2}, \mathrm{NiMo} / \mathrm{Al}_{2} \mathrm{O}_{3}$ showed quite reasonable activities and $\mathrm{NiMo} / \mathrm{Fe}_{2} \mathrm{O}_{3}$ showed worse performance. In all the cases phenol is observed as a major product, which can be formed either by direct demethoxylation of guaiacol to phenol or demethylation of guiacol followed by hydrogenolysis (Nakagawa et al. [12]). It is clearly seen that the product distribution is highly dependent on the type of the support used. Though $\mathrm{NiMo} / \mathrm{TiO}_{2}$ showed moderate conversion compared to $\mathrm{NiMo} / \mathrm{SiO}_{2}$, the high amount (approximately $60 \%$ ) of low oxygen species is observed in the former case. Therefore, we have chosen $\mathrm{NiMo} / \mathrm{TiO}_{2}$ catalyst to study the effect of different reaction parameters on reactivity.

Evolution of the reaction with temperature is presented in Figure 2. As shown from the figure, the conversion is significantly increased with temperature from 200 to $350^{\circ} \mathrm{C}$ and reached approximately $97 \%$ at $350^{\circ} \mathrm{C}$. Initially low amount of phenol, anisole and cresol, high amount of catechol dimethyl ether are observed and catechol is appeared only after $250^{\circ} \mathrm{C}$. The methoxy group that was removed during the formation of phenol was identified in GCMS as methanol. Anisole could be resulted by the demethoxylation from catechol dimethyl ether. Cresol is formed by transalkylation followed by HDO of guaicol. Presence of Bronsted acid sites on the catalyst are evidenced by cresol formation (Zhu et al. [13]). Catechol dimethyl ether and catechol could be resulted by methylation and demethylation of guaiacol, respectively. As increase in the temperature partially deoxygenated products such as, anisole, phenol and cresol are gradually increased at the expense of undesirable products, catechol and catechol dimethyl ether. 


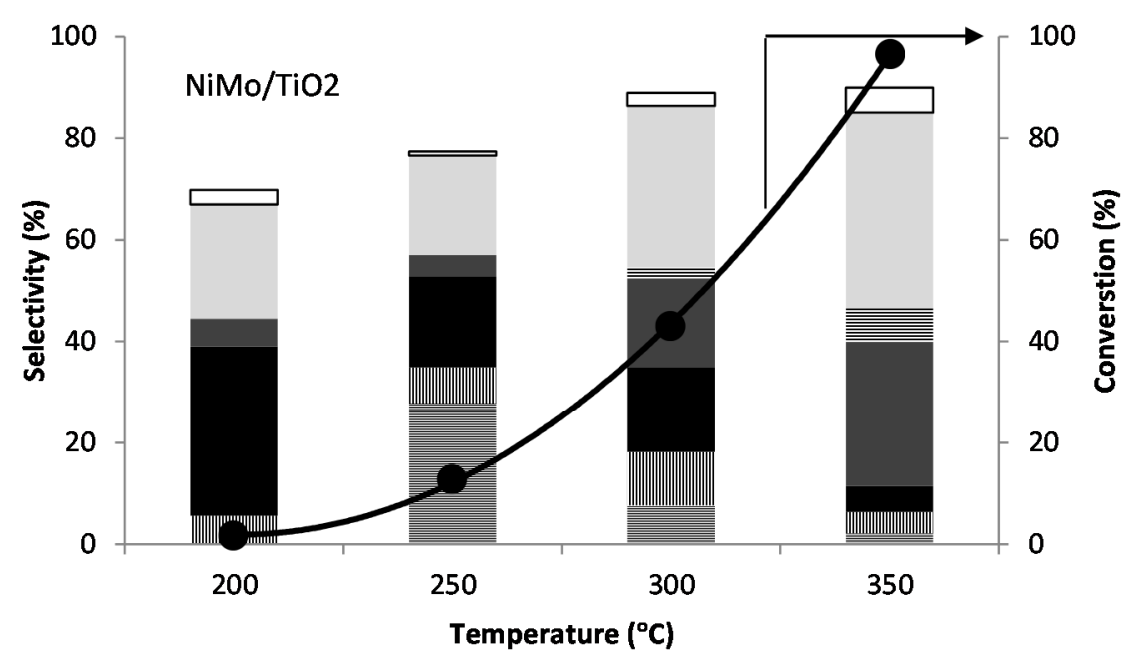

\begin{tabular}{|c|c|c|}
\hline$\square$ Anisole & Phenol & 吾Xylenol \\
\hline Cresol & - Catechol dimethyl ether & IIIII Creosol \\
\hline
\end{tabular}

Figure 2: Effect of temperature on guaiacol conversion and selectivity for $\mathrm{NiMo} / \mathrm{TiO}_{2}$. Reaction conditions, $\mathrm{H}_{2}, 100 \mathrm{psi} ; 10 \mathrm{wt} \%$ catalyst to guaiacol; $5 \mathrm{~h}$.

The quite similar observation is also noted with reaction time and $\mathrm{H}_{2} /$ guaiacol molar ratios (discussed in subsequent sections). Irrespective of the reaction conditions (temperature, reaction time, $\mathrm{H}_{2}$ pressure, and sample weight) catechol and catechol dimethyl ether are gradually reduced which exemplify that deoxygenation of guaiacol is a sequential reaction, with catechol/catechol dimethyl ether as the intermediates to obtain mono-oxygenated compounds. Creosol selectivity is remained unchanged with temperature. At high temperature $\left(350^{\circ} \mathrm{C}\right)$ xylenol is started appearing.

Effect of reaction time on the guaiacol conversion is presented in Figure 3a. With increase in the reaction time the conversion is significantly increased and reached to more than five times of its initial one hour. The catalyst is also quite stable and no deactivation observed over the period of $24 \mathrm{~h}$. The product distribution as a function of time is also shown in Figure 3b. With increase in the contact time between $\mathrm{H}_{2}$, guaiacol, and catalyst, partially deoxygenated products such as anisole, phenol, and cresol started increasing whereas catechol and catechol dimethyl ether are inclined to decrease. 
(a)

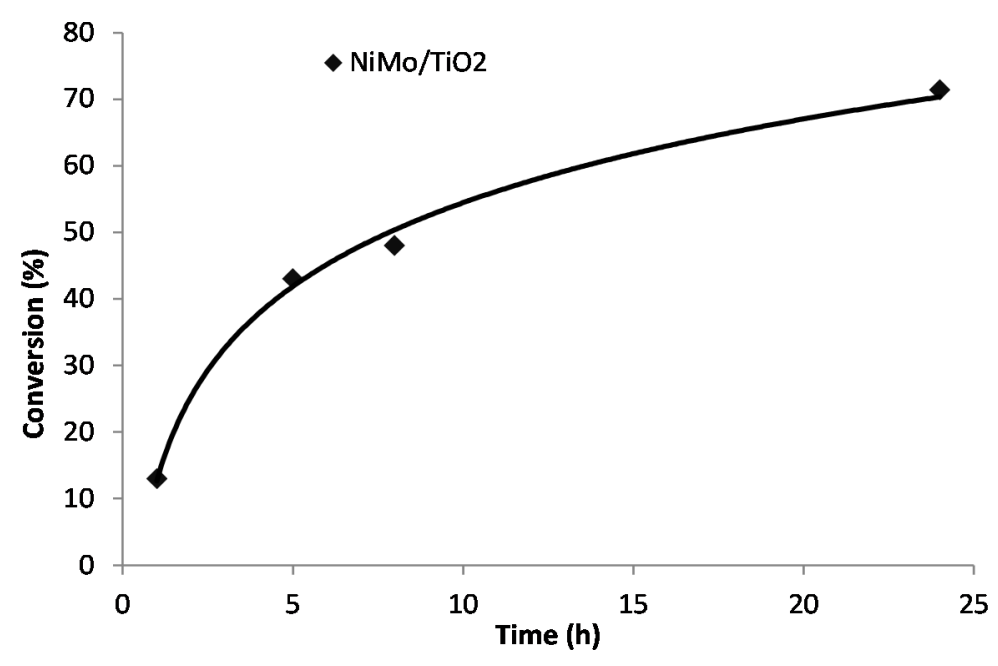

(b)

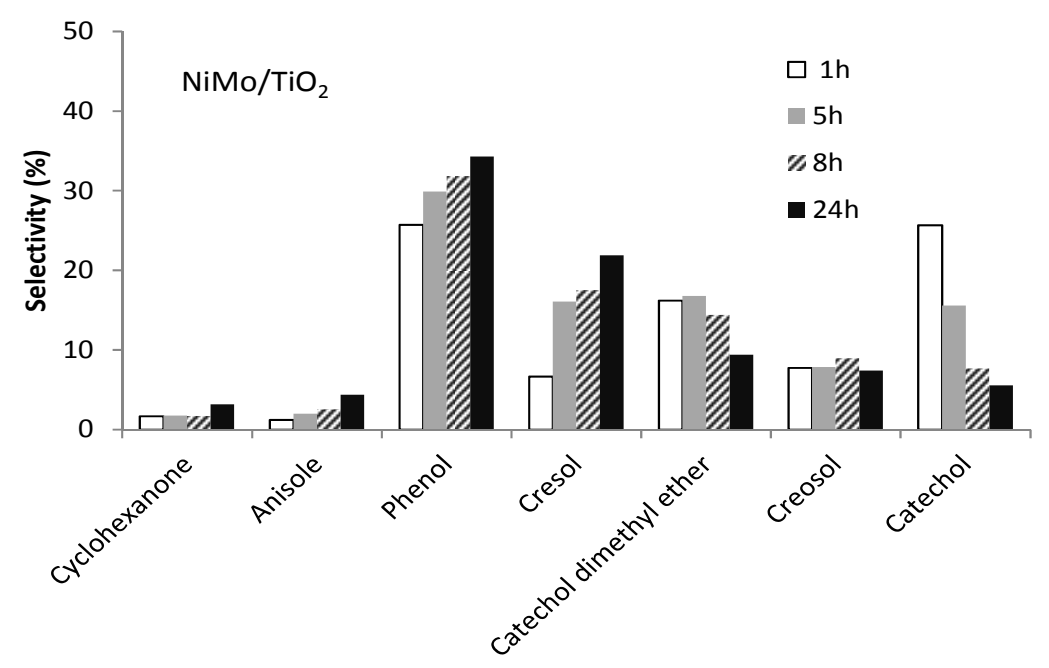

Product distribution

Figure 3: (a) Effect of reaction time on conversion of guaiacol for $\mathrm{NiMo} / \mathrm{TiO}_{2}$ : (b) Effect of reaction time on product distribution for $\mathrm{NiMo} / \mathrm{TiO}_{2}$. Reaction conditions: $\mathrm{H}_{2}, 100 \mathrm{psi} ; 10 \mathrm{wt} \%$ catalyst to guaiacol; $300^{\circ} \mathrm{C}$. 


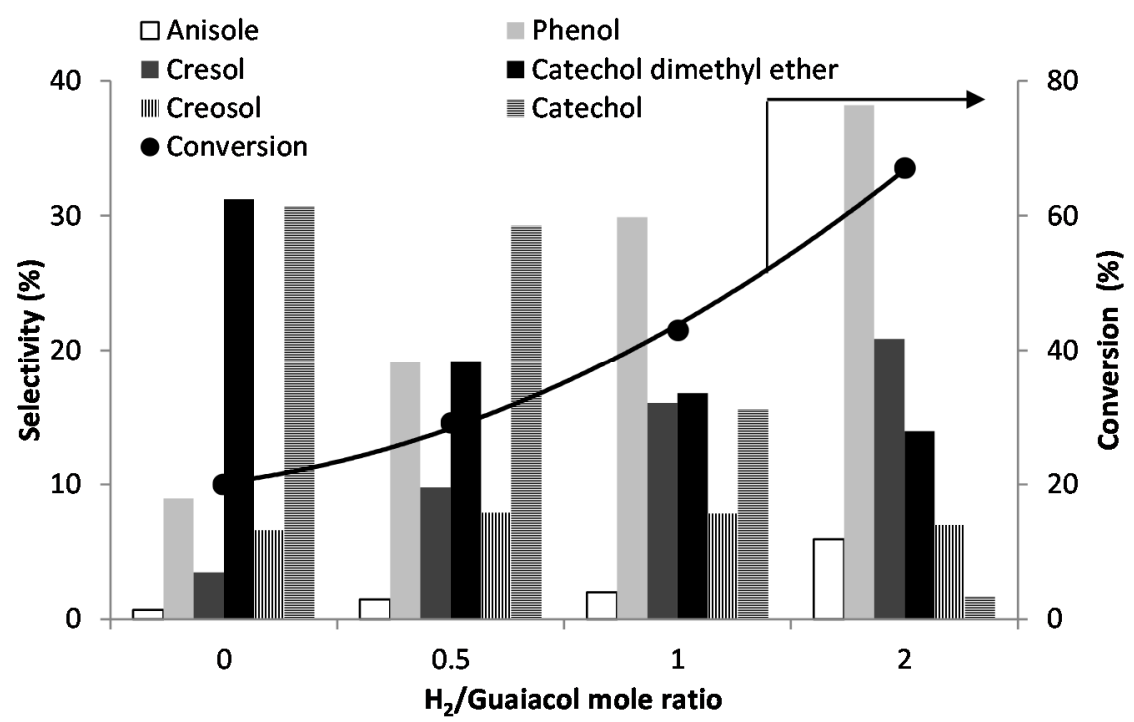

Figure 4: Effect of $\mathrm{H}_{2}$ /guaiacol ratio $\mathrm{NiMo} / \mathrm{TiO}_{2}$. Reaction conditions: $10 \mathrm{wt} \%$ catalyst to guaiacol; $300^{\circ} \mathrm{C} ; 5 \mathrm{~h}$.

Not only the temperature and reaction time but also amount of guaiacol and $\mathrm{H}_{2}$ pressure seems to have an important role on the guaiacol conversion. As increase in the guaiacol amount the conversion decreases with variable products (figure is not shown) attribute to the completion between the guaiacol molecules and acidic sites of support. Effect of $\mathrm{H}_{2}$ /guaiacol mole ratio on guaiacol conversion and main products is presented in Figure 4. Guaiacol conversion was very low in the absence of hydrogen $(<20 \%)$ with catechol dimethyl ether and catechol as the primary products. As $\mathrm{H}_{2}$ pressure increases, the guaiacol conversion is increased significantly from 20 to $67 \%$ (see the figure). Phenol and trans-alkylation product (cresol) are consistently increased. Traces of complete deoxygenated products are seen (not shown in the figure).

The variation of guaiacol conversion with catalyst (blank, bare support and mono- and bi-metallic catalyst) is studied and presented Figure 5 to understand influence of metal and support. Blank (without catalyst) and titania support have showed $10 \pm 2$ and $15 \pm 2 \%$, respectively. Since bare support showed poor performance, the products that observed for $\mathrm{NiMo} / \mathrm{TiO}_{2}$ are ascribed to the metal phase. As seen from the figure, the conversion of $\mathrm{Ni} / \mathrm{TiO}_{2}$ and $\mathrm{Mo} / \mathrm{TiO}_{2}$ is much lower and when $\mathrm{Ni}$ is mixed with Mo the activity increased to almost two times. These results indicate the necessary active sites for hydrogenolysis or transalkylation reactions are provided by the combination of $\mathrm{Ni}$ and Mo metals. The high activity for $\mathrm{NiMo} / \mathrm{TiO}_{2}$ is attributing to the development of metal alloy (NiMo) which supposed to be formed under reduction atmosphere. It is well proved by several researchers that although mono metals are barely active but their combination would become active and can promote their catalytic behaviour (Sun et al. [14]). 


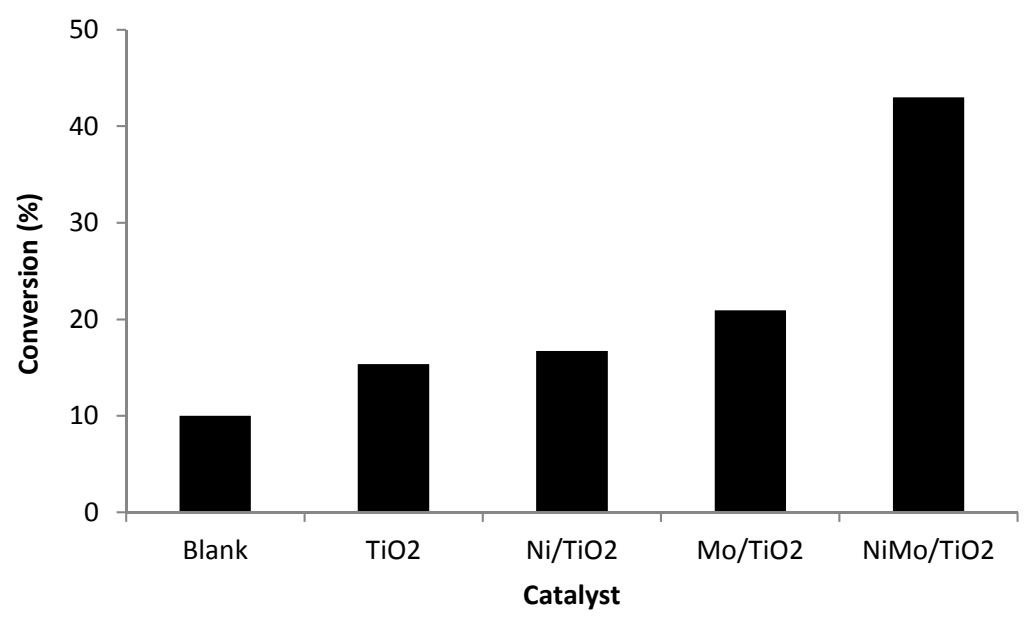

Figure 5: Comparison of conversion of $\mathrm{NiMo} / \mathrm{TiO} 2$ with $\mathrm{Ni} / \mathrm{TiO}_{2}$ and $\mathrm{Mo} / \mathrm{TiO}_{2}$. Reaction conditions: $\mathrm{H}_{2}, 100 \mathrm{psi} ; 10 \mathrm{wt} \%$ catalyst to guaiacol; $300^{\circ} \mathrm{C}$; $5 \mathrm{~h}$.

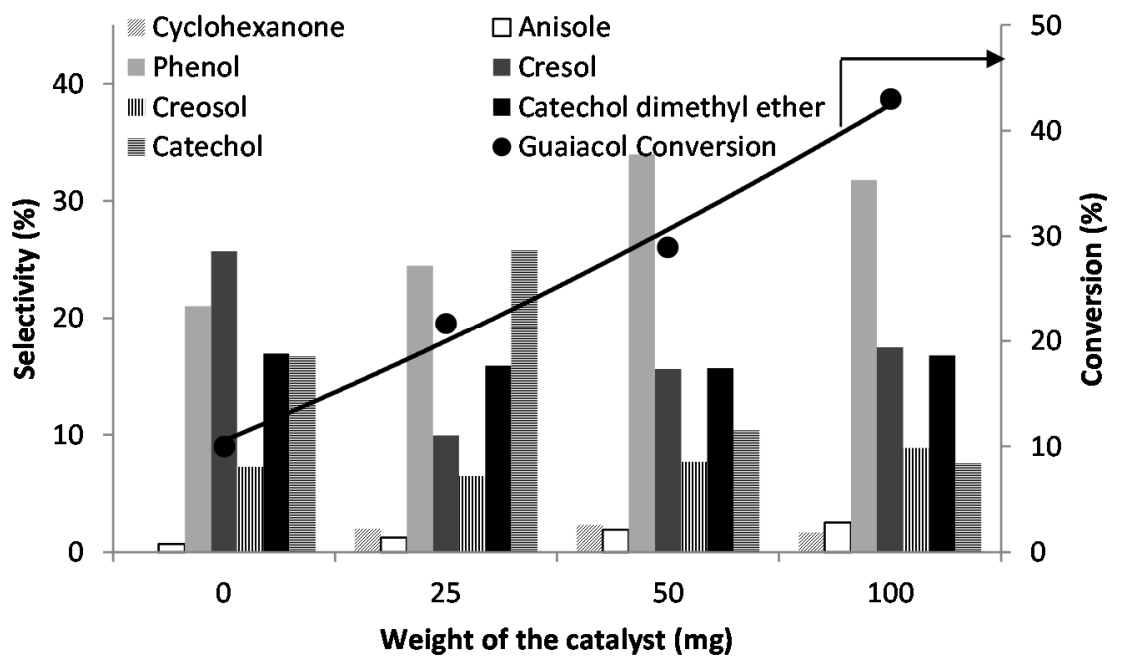

Figure 6: Effect of quantity of $\mathrm{NiMo} / \mathrm{TiO}_{2}$. Reaction conditions: $\mathrm{H}_{2}, 100$ psi; $300^{\circ} \mathrm{C} ; 5 \mathrm{~h}$.

Effect of catalyst quantity is studied and showed in Figure 6. As the catalyst amount increased the conversion is also linearly increased, could be attributed to lowering of the activation energy. From the Figures 4 and 6, it is apparent that both catalyst and $\mathrm{H}_{2}$ together play a significant role for the reaction to proceed. In the absence of catalyst, cresol is formed as major while under catalytic conditions 
traces amount of cyclohexanone is also noticed. Under both catalytic and noncatalytic conditions no difference in catechol dimethyl ether and creosol is found. With increase in the sample weight phenol and anisole are increased and catechol decreased.

Table 1: Conversion and selectivity of $\mathrm{HDO}$ reaction at $350^{\circ} \mathrm{C}, 5 \mathrm{~h}$ and $2: 1$ of $\mathrm{H}_{2}$ :guaiacol over $\mathrm{NiMo} / \mathrm{TiO}_{2}$.

\begin{tabular}{|l|c|}
\hline Entry 1 & $\mathrm{NiMo} / \mathrm{TiO}_{2}(\%)$ \\
\hline Guaiacol conversion & 96.7 \\
\hline Cyclohexanone & 2.8 \\
\hline Anisole & 4.6 \\
\hline Methyl Anisole & 3.1 \\
\hline Phenol & 36.7 \\
\hline Cresol & 27.0 \\
\hline Xylenol & 14.9 \\
\hline Tri methyl Phenol & 0.2 \\
\hline Catechol dimethyl ether & 4.9 \\
\hline Catechol & - \\
\hline
\end{tabular}

The catalyst is also evaluated under optimized conditions (at $350^{\circ} \mathrm{C}$ and $2: 1$ of $\mathrm{H}_{2}$ :guaiacol) and the results are summarized in Table 1. Under these conditions, along with phenol and anisole, heavy compounds such as di- and tri-methyl phenols are emerged and surprisingly, there are no two oxygen components are noted.

\section{Conclusions}

In this work, a series of different NiMo based catalysts were successfully synthetized and tested for the hydrodeoxygenation of guaiacol under relatively low hydrogen pressure and moderate temperature. The performance of the catalyst was studied using $\mathrm{NiMo} / \mathrm{TiO}_{2}$ under different reaction conditions. It is proved that the longer reaction hours, high temperature, $\mathrm{H}_{2}$ pressure and catalyst amount are played positive role in enhancing the conversion and facilitating low oxygenated products. $\mathrm{TiO}_{2}, \mathrm{Ni} / \mathrm{TiO}_{2}$ and $\mathrm{Mo} / \mathrm{TiO}_{2}$ lead to a limited guaiacol conversion, but combination of all these $\left(\mathrm{NiMo} / \mathrm{TiO}_{2}\right)$ performed well. Structural properties of the catalyst need to be determined, yet $\mathrm{NiMo} / \mathrm{TiO}_{2}$ is a promising catalyst for upgrading pyrolysis bio-oil under mild operational conditions.

\section{Acknowledgements}

The authors are grateful to the financial support of the Natural Science and Engineering Research Council of Canada (NSERC). The authors also thank Ragav Sundaresan, Samantha Alcantara, Tanvi Torani for their contribution in catalyst preparation and reaction part, respectively. 


\section{References}

[1] Huber, G. W., Iborra, S. \& Corma, A., Synthesis of Transportation Fuels from Biomass: Chemistry, Catalysts, and Engineering, Chem. Rev., 106, p. 4044, 2006.

[2] McKendry, P., Energy production from biomass (part 1): overview of biomass, Bioresour. Technol., 83, pp. 37, 2002.

[3] Mortensen, P. M., Grunwaldt, J.-D., Jensen, P. A. \& Jensen A. D., Screening of Catalysts for Hydrodeoxygenation of Phenol as a Model Compound for Bio-oil, ACS Catal., 3, pp. 1774-1785, 2013.

[4] González-Borja, M. A. \& Resasco, D. E., Anisole and Guaiacol Hydrodeoxygenation over Monolithic Pt-Sn Catalysts, Energy Fuels, 25, pp. 4155-4162, 2011.

[5] Sun J., Karim, A. M., Zhang, H., Kovarik, L., Li, X. S., Hensley, A. J., McEwen, J.-S., Wang Y., Carbon-supported bimetallic Pd-Fe catalysts for vapor-phase hydrodeoxygenation of guaiacol, J. Catal., 306, pp. 47-57, 2013.

[6] Saidi, M., Samimi, F., Karimipourfard, D., Nimmanwudipong, T., Gates, B. C. \& Rahimpour, M. R., Upgrading of lignin-derived bio-oils by catalytic hydrodeoxygenation, Energy Environ. Sci., 7, pp. 103-129, 2014.

[7] Nimmanwudipong, T., Runnebaum, R. C., Block, D. E. \& Gates, B. C., Catalytic Conversion of Guaiacol Catalyzed by Platinum Supported on Alumina: Reaction Network Including Hydrodeoxygenation Reactions, Energy Fuels, 25, pp. 3417-3427, 2011.

[8] Mortensena, P. M., Grunwaldt, J.-D., Jensena, P. A., Knudsenc, K. G. \& Jensen, A.D., A review of catalytic upgrading of bio-oil to engine fuels, Appl. Catal. A., 407, pp. 1- 19, 2011.

[9] Serrano-Ruiz, J. C. \& Dumesic, J. A., Catalysis for Alternative Energy Generation, Chapter. 2, Guczi, L., Erdőhelyi, A., (eds.) Springer Science and Business Media, New York 2012.

[10] Yang, Y. Q., Tye, C. T., Smith, K. J., Influence of MoS2 catalyst morphology on the hydrodeoxygenation of phenols, Catal. Com., 9, pp. 1364-1368, 2008.

[11] Zhang, X., Long, J., Kong, W., Zhang, Q., Chen, L., Wang, T., Ma, L. \& Li, Y., Catalytic Upgrading of Bio-oil over Ni-Based Catalysts Supported on Mixed Oxides, Energy Fuels, 28, pp. 2562-2570, 2014.

[12] Nakagawa, Y., Ishikawa, M., Tamura, M. \& Tomishige, K., Selective production of cyclohexanol and methanol from guaiacol over Ru catalyst combined with MgO, Green Chem., 16, pp. 2197, 2014.

[13] Zhu, X., Lobban, L. L., Mallinson, R. G. \& Resasco, D. E., Bifunctional transalkylation and hydrodeoxygenation of anisole over a Pt/HBeta catalyst, J. Catal., 281, pp. 21-29, 2011.

[14] Sun, J., Karim, A. M., Zhang, H., Kovarik, L., Li, X. S., Hensley, A. J., McEwen, J.-S. \& Wang, Y., Carbon-supported bimetallic Pd-Fe catalysts for vapor-phase hydrodeoxygenation of guaiacol, J. Catal., 306, pp. 47-57, 2013. 